\title{
APOE epsilon 4, rs405509, and rs440446 promoter and intron-1 polymorphisms and dementia risk in a cohort of elderly Finns-Helsinki Birth Cohort Study
}

\author{
Rantalainen, Ville
}

2019-01

Rantalainen, V , Lahti , J , Kajantie , E , Tienari , P , Eriksson , J G \& Raikkonen , K 2019 , ' APOE epsilon 4, rs405509, and rs440446 promoter and intron-1 polymorphisms and dementia risk in a cohort of elderly Finns-Helsinki Birth Cohort Study ' , Neurobiology of Aging , vol. 73 , ARTN 230.e5 . https://doi.org/10.1016/j.neurobiolaging.2018.09.005

http://hdl.handle.net/10138/274092

https://doi.org/10.1016/j.neurobiolaging.2018.09.005

publishedVersion

Downloaded from Helda, University of Helsinki institutional repository.

This is an electronic reprint of the original article.

This reprint may differ from the original in pagination and typographic detail.

Please cite the original version. 


\title{
$A P O E$ \&4, rs405509, and rs440446 promoter and intron-1 polymorphisms and dementia risk in a cohort of elderly Finns-Helsinki Birth Cohort Study
}

\author{
Ville Rantalainen ${ }^{\mathrm{a}, *}$, Jari Lahti ${ }^{\mathrm{a}}$, Eero Kajantie ${ }^{\mathrm{b}}$, Pentti Tienari ${ }^{\mathrm{c}}$, Johan G. Eriksson ${ }^{\mathrm{d}}$, \\ Katri Raikkonen ${ }^{\mathrm{e}}$ \\ a Department of Psychology and Logopedics, University of Helsinki, Finland; Folkhälsan Research Centre, Helsinki, Finland \\ b Chronic Disease Prevention Unit, National Institute for Health and Welfare, Helsinki, Finland; Hospital for Children and Adolescents, Helsinki \\ University Central Hospital, University of Helsinki, Helsinki, Finland; PEDEGO Research Unit, MRC Oulu, Oulu University Hospital, University of Oulu, \\ Oulu, Finland \\ ${ }^{\mathrm{c}}$ Department of Neurology, Helsinki University Central Hospital; Molecular Neurology, Research Programs Unit, Biomedicum, University of Helsinki, \\ Helsinki, Finland \\ ${ }^{\mathrm{d}}$ Department of General Practice, Primary Health Care, University of Helsinki, Helsinki University Hospital, Helsinki, Finland; Folkhälsan Research \\ Center, Helsinki, Finland; National Institute for Health and Welfare, Helsinki, Finland \\ ${ }^{\mathrm{e}}$ Department of Psychology and Logopedics, University of Helsinki, Helsinki, Finland
}

\section{A R T I C L E I N F O}

\section{Article history:}

Received 19 February 2018

Received in revised form 5 July 2018

Accepted 6 September 2018

Available online 12 September 2018

\section{Keywords:}

Dementia

Alzheimer's disease

APOE

Cohort studies

\begin{abstract}
A B S T R A C T
We tested if the $\varepsilon 4$ major isoform of the $A P O E$ gene and rs405509 and rs440446 promoter and intron- 1 polymorphisms predicted risk of any dementia or Alzheimer's disease with diagnoses derived from the Hospital Discharge and Causes of Death Registers in 1453 participants of the Helsinki Birth Cohort Study. We used Cox proportional hazard models adjusted for sex, year of birth, maximum lifetime occupational status and education, and diagnoses of stroke, coronary heart disease, mood disorders, and depressive symptoms. APOE $\varepsilon 4$ predicted higher risk of any dementia (hazard ratios $>3.68$; $95 \%$ confidence interval [CI] 1.76, 7.70) across all statistical models, and when adjusted for rs405509 and rs440446. The number of minor alleles in rs 405509 or rs 440446 was not associated with dementia risk (hazard ratios $<1.43 ; 95 \%$ CI $0.87,2.36$ ). As rs 405509 or rs 440446 has been associated with nonpathological cognitive aging in this and other cohorts independent of the $A P O E$ major isoforms, these findings lend credence that $A P O E$ locus may be linked with dementia risk and nonpathological cognitive aging via separate mechanisms.
\end{abstract}

(c) 2018 Elsevier Inc. All rights reserved.

\section{Introduction}

The $\varepsilon 4$ major isoform of the $A P O E$ gene is a well-documented risk factor for Alzheimer's disease (AD) (Corder et al., 1993), dementia with Lewy bodies (Bras et al., 2014) as well as vascular dementia (Sun et al., 2015), and has also been found to be associated with cognitive functioning without dementia (Wisdom et al., 2011). In addition to the $\varepsilon 4$ major isoform, the functional polymorphism rs405509 in the APOE gene promoter region has been found to be associated with AD risk (Lambert et al., 1998) as well as nonpathological cognitive aging (Rantalainen et al., 2016). However, research on this polymorphism has not been unanimous. Some studies have found higher AD risk associated with the major allele

\footnotetext{
* Corresponding author at: Department of Psychology and Logopedics, University of Helsinki, Finland; Folkhälsan Research Centre, Helsinki, Finland. Tel.: +358 504486475; fax: +358 919129521.

E-mail address: ville.rantalainen@helsinki.fi (V. Rantalainen).
}

(Beyer et al., 2005; Myllykangas et al., 2002) and others with the minor allele (Lambert et al., 1998; Nicodemus et al., 2004). Furthermore, some studies have reported risks differing with ethnicity (Lambert et al., 2002) or age of dementia onset (Beyer et al., 2005). It has also been unclear whether the promoter polymorphism's effects are truly independent of or due to linkage disequilibrium with APOE major isoforms (Jun et al., 2012; Roses et al., 2010).

It has been suggested that the APOE locus is associated with nonpathological cognitive aging and dementia risk via separate mechanisms (Deary et al., 2002). However, there have thus far been no studies to report associations of $A P O E$ major isoforms and rs405509 promoter polymorphisms with both outcomes in a single study population. We recently reported that while the $A P O E$ major isoforms were not associated with cognitive ability in elderly men from the Helsinki Birth Cohort Study (HBCS), the number of minor alleles in rs405509 and in another functional polymorphism, rs440446 in the APOE gene intron-1, predicted better preserved 
cognitive ability independent of the APOE major isoforms (Rantalainen et al., 2016). Here we extend these analyses and study whether these genetic variants predict dementia risk in participants derived from this same study population.

\section{Methods}

\subsection{Participants}

The HBCS includes a random sample of 2003 participants. Of them, data on $A P O E$ major isoforms, rs405509, rs440446, and dementia diagnoses were available for 1453 participants (72.5\%).

Compared with the rest of the cohort, the participants in the analytic sample were more likely to have attained maximum lifetime upper clerical occupation $(p<0.001)$ and tertiary education $(p$ $<0.001)$.

\subsection{Ethics statement}

The HBCS has been approved by the Ethics Committee of the National Public Health Institute and the Coordinating Ethics Committee of the Hospital District of Helsinki and Uusimaa.

\subsection{Genotyping}

Genotyping and linkage disequilibria between markers have been described (Rantalainen et al., 2016). In this sample, the biallelic sites that are used to determine APOE major isoforms ( $\operatorname{Arg} 112 /$ Cys and Arg158/Cys) and rs405509 and rs440446 were at HardyWeinberg equilibrium (not shown).

\subsection{Dementia diagnoses}

Diagnoses of any organic dementias, given in inpatient (1969-2013) and outpatient (1998-2013) specialty care (codes 290.00-290.10 from International Classification of Diseases [ICD]-8, 290, 2912A, 2928C, 2941A, 3310A, and 3311A from ICD-9, and F00, F01, F03, F051, and G30 from ICD-10) and AD (codes 331.0 and 290.1 from ICD-9, and G30 and F00 from ICD-10) until the end of 2013 were derived from the Finnish Hospital Discharge and Causes of Death Registers.

\subsection{Covariates and confounders}

These included the participant's sex, year of birth extracted from hospital records, highest attained occupational status (manual worker, junior clerical, and senior clerical), and highest attained level of education in adulthood (lower secondary or less, upper secondary, lower tertiary, and upper tertiary) recorded at 5-year intervals between 1970 and 2000 derived from Statistics Finland, and diagnoses of stroke (codes 430-434 and 436-437 from ICD-8 and -9, 438 from ICD-9, and I60-I69 from ICD-10) (Barker et al., 2005), coronary heart disease (codes $410-414$ from ICD-8 and -9 and I21-I25 from ICD-10) (Osmond et al., 2007), and mood disorders (codes 296, 298.00, 3004, and 301.10 from ICD-8; 296, 3004A, and 3011D from ICD-9; and F30-F39 from ICD-10) until the end of 2013 derived from the Hospital Discharge Register, depressive symptoms reported using the Beck Depression Inventory (Beck et al., 1961) at the time of drawing blood for DNA extraction, and the first 3 multidimensional scaling components derived from genomewide data to account for population stratification.

\subsection{Statistical methods}

Cox Proportional Hazards models examined the associations between $A P O E \& 4$ ( $\varepsilon 4$ carriers vs. noncarriers as referent), and the number of minor alleles in rs405509 and in rs440446 and risk of any dementia and $\mathrm{AD}$ (no dementia as referent). The participants were followed up until their first hospitalization for any dementia, death, migration, or until December 31, 2013. We first examined the associations of $A P O E \varepsilon 4$, rs405509, and rs440446 with dementia risk in separate models and then entered rs405509 and rs440446 in the models with $A P O E \& 4$. We also tested the associations of rs405509 and rs440446 with dementia risk separately in $\varepsilon 4$ carriers and $\varepsilon 3 / 3$ homozygotes, which enables unambiguous haplotyping (see Myllykangas et al., 2002; Rantalainen et al., 2016; Strandberg et al., 2005; Viiri et al., 2008) as rs405509 and rs440446 are in linkage disequilibrium with the $\varepsilon 2$ or $\varepsilon 4$ major isoforms (Jun et al., 2012; Rantalainen et al., 2016; Roses et al., 2010). The analyses were adjusted first for sex, year of birth, and population stratification, and then for the other covariates.

\section{Results}

Sample characteristics according to $A P O E$ major isoforms are presented in Supplementary Table 1.

$A P O E \& 4$ was associated with a higher risk of any dementia in all statistical models (hazard ratios [HRs] $>3.68$; 95\% confidence interval $[\mathrm{CI}] 1.76,7.70$ ) (Table 1, Supplementary Fig. 1). The number of minor alleles in rs405509 or rs440446 was not significantly associated with any dementia risk in any of the models (all HRs $<1.43$; $95 \% \mathrm{CI} 0.87,2.36$ ), and was not either associated with any dementia risk in $A P O E \varepsilon 3 / 3$ homozygotes (all HRs $<0.81 ; 95 \% \mathrm{CI} 0.33,1.99$ ) or

Table 1

Risk of any dementia according to APOE $\varepsilon 4$ and rs405509 and rs440446 polymorphisms

\begin{tabular}{|c|c|c|c|c|c|c|c|c|}
\hline \multirow[t]{2}{*}{ Genotype } & \multicolumn{2}{|l|}{ Model $1^{\text {a }}$} & \multicolumn{2}{|l|}{ Model $2^{\mathrm{b}}$} & \multicolumn{2}{|l|}{ Model $3^{c}$} & \multicolumn{2}{|l|}{ Model $4^{\mathrm{d}}$} \\
\hline & $\overline{\mathrm{HR}}(95 \% \mathrm{CI})$ & $p$ & HR (95\% CI) & $p$ & $\overline{\mathrm{HR}(95 \% \mathrm{CI})}$ & $p$ & $\overline{\mathrm{HR}(95 \% \mathrm{CI})}$ & $p$ \\
\hline \multicolumn{9}{|c|}{$A P O E \varepsilon 4$ and number of rs405509 minor T alleles and rs440446 minor C alleles in separate models } \\
\hline APOE \& 4 & $3.70(1.75,7.64)$ & 0.001 & $3.86(1.84,8.10)$ & $<0.001$ & $3.68(1.76,7.70)$ & 0.001 & $3.83(1.82,8.04)$ & $<0.001$ \\
\hline rs405509T & $1.40(0.86,2.29)$ & 0.182 & $1.41(0.86,2.31)$ & 0.172 & $1.41(0.86,2.32)$ & 0.176 & $1.43(0.87,2.36)$ & 0.158 \\
\hline rs440446C & $0.76(0.41,1.42)$ & 0.394 & $0.75(0.40,1.40)$ & 0.363 & $0.76(0.41,1.43)$ & 0.401 & $0.76(0.40,1.43)$ & 0.387 \\
\hline \multicolumn{9}{|c|}{$A P O E \& 4$ and number of rs 405509 minor $\mathrm{T}$ alleles in the same model } \\
\hline APOE \& 4 & $3.77(1.67,8.52)$ & 0.001 & $4.06(1.77,9.30)$ & 0.001 & $3.83(1.69,8.71)$ & 0.001 & $3.96(1.74,9.05)$ & 0.001 \\
\hline rs405509T & $0.95(0.54,1.68)$ & 0.864 & $0.93(0.53,1.63)$ & 0.789 & $0.94(0.53,1.67)$ & 0.829 & $0.95(0.54,1.67)$ & 0.850 \\
\hline \multicolumn{9}{|c|}{$A P O E \& 4$ and number of rs 440446 minor $C$ alleles in the same model } \\
\hline APOE \& 4 & $3.14(1.41,6.96)$ & 0.005 & $3.29(1.48,7.31)$ & 0.003 & $3.14(1.41,6.97)$ & 0.005 & $3.30(1.48,7.36)$ & 0.004 \\
\hline rs440446C & $1.00(0.51,1.94)$ & 0.988 & $0.96(0.49,1.88)$ & 0.909 & $1.00(0.51,1.96)$ & 1.000 & $0.99(0.50,1.96)$ & 0.980 \\
\hline
\end{tabular}

Key: HR, hazard ratio; $95 \% \mathrm{CI}, 95 \%$ confidence interval.

a Model 1 adjusting for sex, year of birth, and population stratification.

b Model 2 adjusting for sex, year of birth, maximum attained lifetime occupational status, and population stratification.

c Model 3 adjusting for sex, year of birth, maximum attained lifetime educational status, and population stratification.

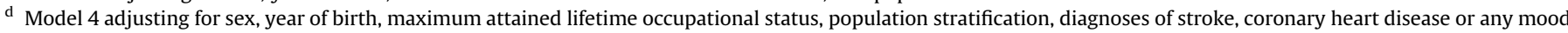
disorder, and BDI score. 
APOE \&4 carriers (all HRs $<1.09$; 95\% CI 0.39, 3.06) (for any dementia, $\mathrm{n}=11$ in $A P O E \varepsilon 3 / 3$ homozygotes and $\mathrm{n}=20$ in APOE \&4 carriers). When we entered APOE \&4 simultaneously with rs 405509 and rs440446 in respective models, $A P O E \varepsilon 4$ remained a significant predictor of dementia risk (Table 1 ). In analyses with risk of $A D$, the results were similar (Supplementary Table 2; data of stratified analyses in $A P O E \varepsilon 3 / 3$ homozygotes and $A P O E \varepsilon 4$ carriers not shown, $\mathrm{n}=7$ and $\mathrm{n}=16$ with $\mathrm{AD}$, respectively).

\section{Discussion}

Our result is in accordance with the suggestion that the APOE gene may be associated with dementia risk and nonpathological cognitive aging via separate mechanisms (Deary et al., 2002). Together with the finding that rs 405509 and rs440446, but not $\varepsilon 4$, were associated with nonpathological cognitive aging (Rantalainen et al., 2016), the result suggests that the APOE locus may be linked with dementia risk via an isoform-dependent mechanism and with nonpathological cognitive aging via an isoform-independent mechanism in this cohort. However, further studies are needed to determine if a similar pattern of associations is found in other samples derived from 1 study population.

Our results replicate the expected association between APOE $\varepsilon 4$ and a higher risk of any dementia and AD (Corder et al., 1993; Sun et al., 2015). These associations were independent of participant's sex, year of birth, highest attained lifetime occupation and level of education, diagnoses of stroke, cardiovascular disease or any mood disorder, and depressive symptoms, as well as the number of minor alleles in rs405509 or rs 440446 . However, the number of minor alleles in rs405509 or rs440446 was not associated with risk of dementia. This latter finding is in disagreement with some (Beyer et al., 2005; Lambert et al., 1998; Myllykangas et al., 2002) but not all (Jun et al., 2012) previous studies. Our study is unable to confirm or refute the possibility that these discrepancies may be due to ethnicity (Lambert et al., 2002) or age of dementia onset (Beyer et al., 2005).

Strengths of this study include availability of data on dementia diagnoses from national registers in a well-characterized lifespan longitudinal cohort followed up to 69-79 years of age. Our study has the major limitation of a small sample size and a small number of dementia or $\mathrm{AD}$ cases. Our findings should therefore be considered preliminary and await replication in larger samples with lifespan data on nonpathological cognitive aging and dementia. However, dementia prevalence $(2.1 \%)$ in our sample is similar to Finnish nation-level estimates (2.4\%) (Prince et al., 2015), and the relative contributions of $A P O E \varepsilon 4$, rs405509, and rs440446 to dementia risk are less likely to change as our cohort ages. As the effect of $A P O E \& 4$ on dementia risk diminishes after age 70 years (Farrer et al., 1997), and as rs405509 and rs440446 are in linkage disequilibrium with $\varepsilon 4$ (Jun et al., 2012; Rantalainen et al., 2016; Roses et al., 2010), the proportion of the rs405509T and rs440446G alleles, that are more common in $\varepsilon 4$ carriers with dementia, will likely diminish according to age as well, and an increasing proportion of carriers of these alleles among participants who receive a dementia diagnosis will likely be $\varepsilon 4$ noncarriers. As the cohort was born in 1930s and 1940s, generalizations to more recent cohorts cannot be made. This however remains an unavoidable limitation of studying aging-related diseases in today's elderly. Finally, residual confounding cannot be entirely excluded.

\section{Disclosure statement}

The authors have no actual or potential conflicts of interest.

\section{Acknowledgements}

The Helsinki Birth Cohort Study has been funded by The Academy of Finland (grant numbers 269925, 311617, 127437, 129306 , 130326, 134791, and 263924), the Finnish Diabetes Research society, Folkhälsan Research Foundation, Novo Nordisk Foundation, Finska Läkaresällskapet, Signe and Ane Gyllenberg Foundation, Sigrid Juselius Foundation, Foundation for Pediatric Research, University of Helsinki, Ministry of Education, Ahokas Foundation, Emil Aaltonen Foundation, Juho Vainio Foundation, Foundation for Cardiovascular Research, Helsinki University Hospital, and the European Commission within the 7th Framework Programme (DORIAN, grant agreement no. 278603), European Union Horizon 2020 programme (DYNAHEALTH grant no. 633595) and European Union Horizon 2020 programme (LifeCycle grant no. 733206) and European Union Horizon 2020 programme RECAP Research on Children and Adults Born Preterm grant no. 733280).

\section{Appendix A. Supplementary data}

Supplementary data associated with this article can be found, in the online version, at https://doi.org/10.1016/j.neurobiolaging.2018. 09.005 .

\section{References}

Barker, D.J., Osmond, C., Forsén, T.J., Kajantie, E., Eriksson, J.G., 2005. Trajectories of growth among children who have coronary events as adults. N. Engl. J. Med. 353, 1802-1809.

Beck, A.T., Ward, C.H., Mendelson, M., Mock, J., Erbaugh, J., 1961. An inventory for measuring depression. Arch. Gen. Psychiatry 4, 561-571.

Beyer, K., Lao, J.L., Latorre, P., Ariza, A., 2005. Age at onset an essential variable for the definition of genetic risk factors for sporadic Alzheimer's disease. Ann. N. Y Acad. Sci. 1057, 260-278.

Bras, J., Guerreiro, R., Darwent, L., Parkkinen, L., Ansorge, O., Escott-Price, V. Hernandez, D.G., Nalls, M.A., Clark, L.N., Honig, L.S., Marder, K., Van Der Flier, W.M., Lemstra, A., Scheltens, P., Rogaeva, E., St George-Hyslop, P., Londos, E., Zetterberg, H., Ortega-Cubero, S., Pastor, P., Ferman, T.J., GraffRadford, N.R., Ross, O.A., Barber, I., Braae, A., Brown, K., Morgan, K., Maetzler, W. Berg, D., Troakes, C., Al-Sarraj, S., Lashley, T., Compta, Y., Revesz, T., Lees, A. Cairns, N., Halliday, G.M., Mann, D., Pickering-Brown, S., Dickson, D.W., Singleton, A., Hardy, J., 2014. Genetic analysis implicates APOE, SNCA and suggests lysosomal dysfunction in the etiology of dementia with Lewy bodies. Hum. Mol. Genet. 23, 6139-6146.

Corder, E.H., Saunders, A.M., Strittmatter, W.J., Schmechel, D.E., Gaskell, P.C. Small, G.W., Roses, A.D., Haine,s, J.L., Pericak-Vance, M.A., 1993. Gene dose of apolipoprotein E type 4 allele and the risk of Alzheimer's disease in late onset families. Science 261, 921-923.

Deary, I.J., Whiteman, M.C., Pattie, A., Starr, J.M., Hayward, C., Wright, A.F. Carothers, A., Whalley, L.J., 2002. Cognitive change and the APOE $\varepsilon 4$ allele. Nature 418, 932.

Farrer, L.A., Cupples, L.A., Haines, J.L., Hyman, B., Kukull, W.A., Mayeux, R., Myers, R. Pericak-Vance, M.A., Risch, N., van Duijn, C.M., 1997. For the APOE and Alzheimer disease meta-analysis consortium. Effects of age, sex, and ethnicity on the association between apolipoprotein E genotype and Alzheimer disease A meta-analysis. JAMA 278, 1349-1356.

Jun, G., Vardarajan, B.N., Buros, J., Yu, C.-E., Hawk, M.V., Dombroski, B.A. Crane, P.K., Larson, E.B., Mayeux, R., Haines, J.L., Lunetta, K.L., PericakVance, M.A., Schellenberg, G.D., Farrer, L.A., 2012. Comprehensive search for Alzheimer disease susceptibility loci in the APOE region. Arch. Neurol. 69, $1270-1279$.

Lambert, J.-C., Berr, C., Pasquier, F., Delacourte, A., Frigard, B., Cottel, D., PérezTur, J., Mouroux, V., Mohr, M., Cécyre, D., Galasko, D., Lendon, C., Poirier, J. Hardy, J., Mann, D., Amouyel, P., Chartier-Harlin, M.-C., 1998. Pronounced impact of Th1/E47cs mutation compared with -491 AT mutation on neural APOE gene expression and risk of developing Alzheimer's disease. Hum. Mol. Genet. 7, 1511-1516.

Lambert, J.-C., Araria-Goumidi, L., Myllykangas, L., Ellis, C., Wang, J.C., Bullido, M.J. Harris, J.M., Artiga, M.J., Hernandez, D., Kwon, J.M., Frigard, B., Petersen, R.C., Cumming, A.M., Pasquier, F., Sastre, I., Tienari, P.J., Frank, A., Sulkava, R., Morris, J.C., St Clair, D., Mann, D.M., Wavrant-DeVrièze, F., EzquerraTrabalon, M., Amouyel, P., Hardy, J., Haltia, M., Valdivieso, F., Goate, A.M., PérezTur, J., Lendon, C.L., Chartier-Harlin, M.C., 2002. Contribution of APOE promoter polymorphisms to Alzheimer's disease risk. Neurology 59, 59-66.

Myllykangas, L., Polvikoski, T., Reunanen, K., Wavrant-De Vrieze, F., Ellis, C. Hernandez, D., Sulkava, R., Kontula, K., Verkkoniemi, A., Notkola, I.-L., Hardy, J., Pérez-Tur, J., Haltia, M.J., Tienari, P.J., 2002. ApoE ع3-haplotype 
modulates Alzheimer beta-amyloid deposition in the brain. Am. J. Med. Genet. 114, 288-291.

Nicodemus, K.K. Stenger, JE, Schmechel, D.E, Welsh-Bohmer K.A. Saunders, A.M., Roses, A.D., Gilbert, J.R., Vance, J.M., Haines, J.L., PericakVance, M.A., Martin, E.R., 2004. Comprehensive association analysis of APOE regulatory region polymorphisms in Alzheimer disease. Neurogenetics 5, $201-208$.

Osmond, C., Kajantie, E., Forsén, T.J., Eriksson, J.G., Barker, D.J., 2007. Infant growth and stroke in adult life. The Helsinki birth cohort study. Stroke 38, $264-270$.

Prince, M., Wimo, A., Guerchet, M., Ali, G.-C., Wu, Y.-T., Prina, M., 2015. In: World Alzheimer report 2015: the global impact of dementia - an analysis of prevalence, incidence, cost and trends, 84. Alzheimers Dis Int, London.

Rantalainen, V., Lahti, J., Henriksson, M., Kajantie, E., Tienari, P., Eriksson, J.G., Raikkonen, K., 2016. APOE and aging-related cognitive aging in a longitudinal cohort of men. Neurobiol. Aging 44, 151-158.
Roses, A., Lutz, M.W., Amrine-Madsen, H., Saunders, A.M., Crenshaw, D.G. Sundseth, S.S., Huentelman, M.J., Welsh-Bohmer, K.A., Reiman, E.M., 2010 A TOMM40 variable-length polymorphism predicts the age of late-onset Alzheimer's disease. Pharmacogenomics J. 10, 375-384.

Strandberg, T.E., Pitkälä, K., Eerola, J., Tilvis, R., Tienari, P.J., 2005. Interaction of herpesviridae, APOE gene, and education in cognitive impairment. Neurobiol. Aging 26, 1001-1004.

Sun, J.-H., Tan, L., Wang, H.-F., Tan, M.-S., Tan, L., Li, J.-Q., Xu, W., Zhu, X.-C., Jiang, T. Yu, J.-T., 2015. Genetics of vascular dementia: systematic review and metaanalysis. J. Alzheimers Dis. 46, 611-629.

Viiri, L.E., Viiri, K.M., Ilveskoski, E., Huhtala, H., Mäki, M., Tienari, P.J., Perola, M., Lehtimäki, T., Karhunen, P.J., 2008. Interactions of functional apolipoprotein E gene promoter polymorphisms with smoking on aortic atherosclerosis. Circ. Cardiovasc. Genet. 1, 107-116.

Wisdom, N.M., Callahan, J.L., Hawkins, K.A., 2011. The effects of apolipoprotein E on nonimpaired cognitive functioning: a meta-analysis. Neurobiol. Aging 32, 63-74. 